\title{
Duodenal duplication cyst presenting with gastric outlet obstruction in an adult male
}

A 25-year-old man presented with postprandial vomiting and abdominal pain. He had no significant past medical history and had a normal physical examination. Duodenoscopy and endoscopic ultrasound (EUS) revealed an obstructing, intra-luminal, cystic mass in the third part of the duodenum (D3) ( $\bullet$ Fig. 1).

It occupied the entire duodenal lumen, correlating with computed tomography images ( $\bullet$ Fig. 2). EUS and magnetic resonance imaging suggested a benign cyst (๑ Fig. 3).

The surgical approach involved an upper midline laparotomy with wedge excision of the duodenal wall incorporating the cyst, followed by primary closure of the duodenum. Histological examination demonstrated the duodenal wall with a subjacent cyst containing blood and lined by histiocytes. Bile was noted within the wall and no epithelial lining was identified. The radiological and histological features were in keeping with a duodenal duplication cyst.

Duodenal duplication cyst is a rare benign congenital anomaly acquired during embryonic development of the digestive system [1], with a prevalence of less than 1 per 100000 live births [2]. Features include the presence of an intimate attachment to the native gastrointestinal tract, a smooth muscle coat, and an alimentary mucosal lining. Classically, they are located in the second or third part of the duodenum and share a common wall, communicating with the duodenal lumen in $25 \%$ of cases [3]. Presentation is usually in infancy or childhood [4], typically with nausea and vomiting, and pancreatitis is the most common complication [2]. Presentation in adulthood is rare. It should be noted that there are reports of malignant transformation in the literature [5]. Treatment is either endoscopic or surgical and should be considered in all patients [2]. Intraluminal cysts may be treated endoscopically, but those that cannot be approached endoscopically will require an open procedure with total cyst excision or marsupialization [2].

Endoscopy_UCTN_Code_CCL_1AB_2AZ_3AZ

Competing interests: None

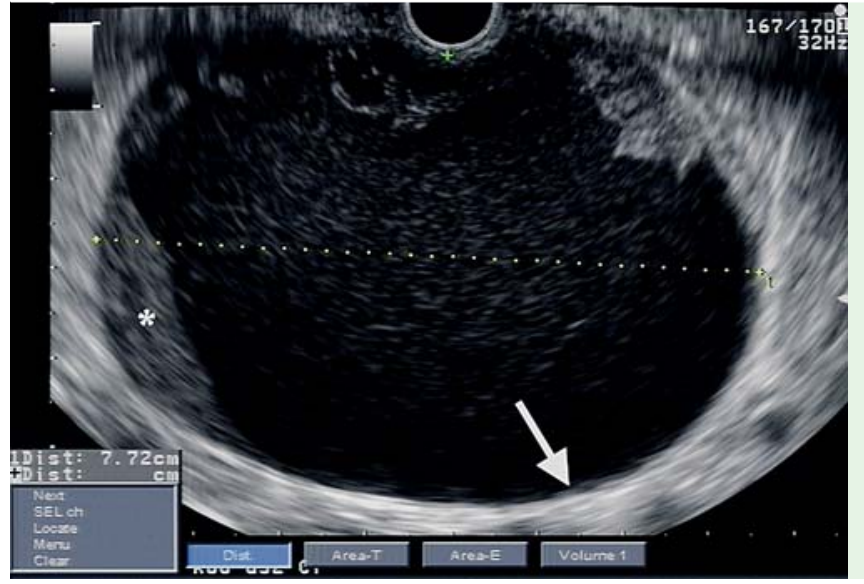

Fig. 1 Endoscopic ultrasound image of an intraluminal cystic lesion in D3, occupying entire duodenal lumen of a young man presenting with postprandial vomiting and abdominal pain. The lesion is fluid filled, containing echogenic debris adherent to its wall (asterisk). The wall is not thickened and no nodules are visible (white arrow).

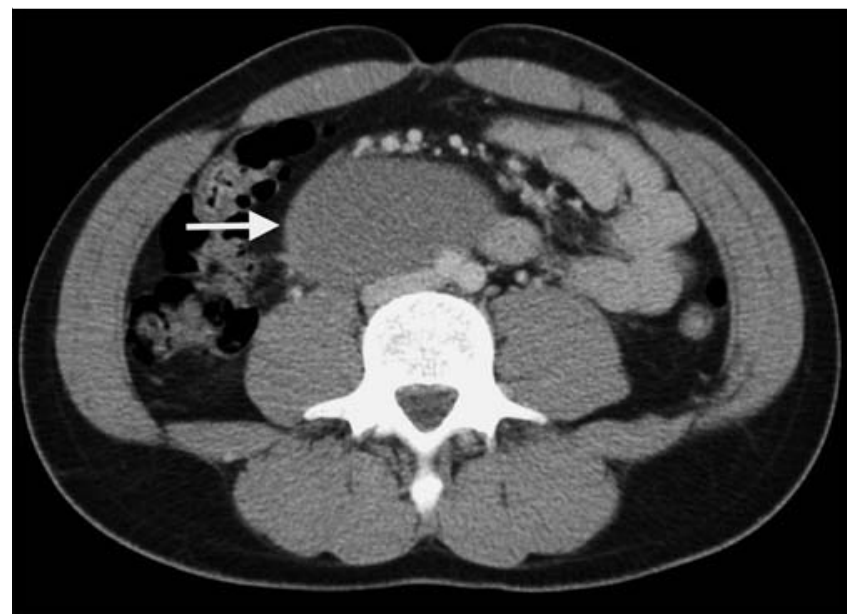

Fig. 2 Computed tomography (CT) image showing a large cystic, intraluminal lesion $(7.8 \mathrm{~cm} \times 4.7 \mathrm{~cm})$ in the third part of the duodenum (arrow).

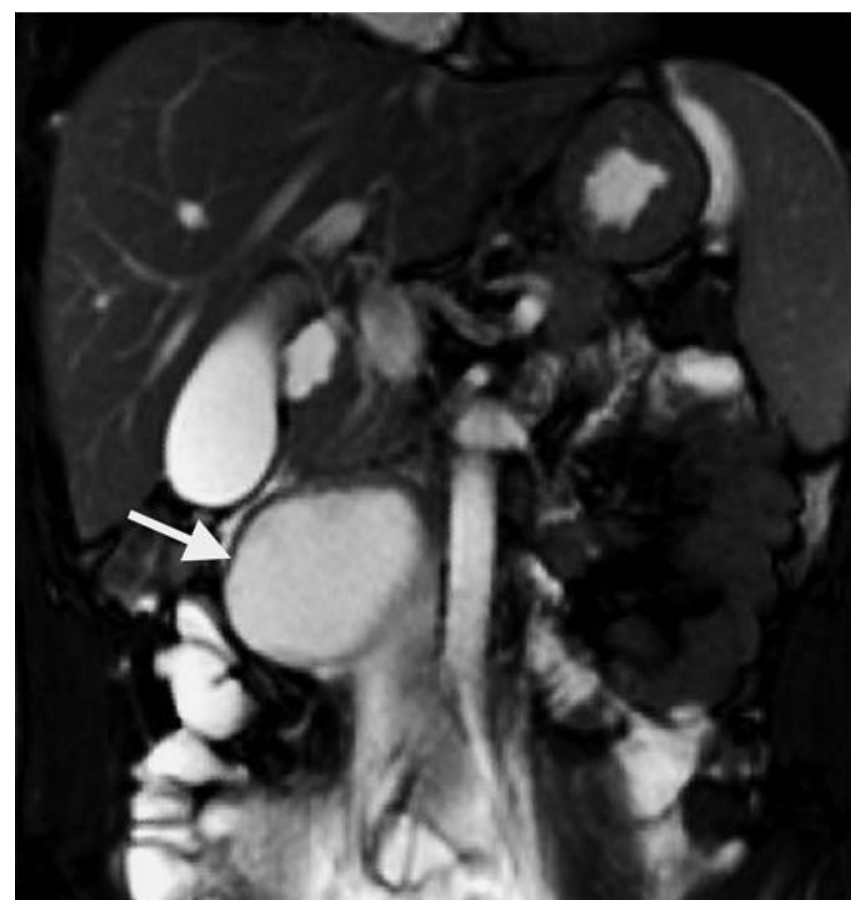

Fig. 3 Magnetic resonance (MR) image showing a $6.6 \mathrm{~cm} \times 4 \mathrm{~cm}$ lesion with rim enhancement and containing proteinaceous material (arrow). 
A. McArdle, J. B. Conneely, N. Ravi, J. V. Reynolds

Department of Clinical Surgery, St James's Hospital and Trinity College Dublin, Dublin, Ireland

\section{References}

1 Guarise A, Faccioli N, Ferrari $M$ et al. Duodenal duplication cyst causing severe pancreatitis: imaging findings and pathological correlation. World J Gastroenterol 2006; 12: $1630-1633$

2 Chen JJ, Lee HC, Yeung CY et al. Meta-analysis: the clinical features of the duodenal duplication cyst. J Pediatr Surg 2010; 45: $1598-1606$
3 Trobs RB, Hemminghaus M, Cernaianu G, Liermann $D$. Stone-containing periampullary duodenal duplication cyst with aberrant pancreatic duct. J Pediatr Surg 2009; 44: $33-35$

4 Merrot T, Anastasescu R, Pankevych $T$ et al. Duodenal duplications. Clinical characteristics, embryological hypotheses, histological findings, treatment. Eur J Pediatr Surg 2006; 16: $18-23$

5 Coit DG, Mies C. Adenocarcinoma arising within a gastric duplication cyst. J Surg Oncol 1992; 50: 274-277
Bibliography

DOI $10.1055 / \mathrm{s}-0030-1256857$

Endoscopy 2011; 43: E352 -E353

(c) Georg Thieme Verlag KG Stuttgart · New York . ISSN 0013-726X

\section{Corresponding author}

Dr. A. McArdle

Department of Clinical Surgery

St James's Hospital and Trinity College Dublin

Dublin

Ireland

adrian_mcardle@yahoo.co.uk 